\title{
Eddy Current Losses in Solid Pole Shoes in a Two-Pole Permanent Magnet Motor
}

\author{
Boel Ekergård1, Mats Leijon² \\ ${ }^{1}$ Department of Industrial Economics, Electrical and Mechanical Engineering, University West, Trollhättan, Sweden \\ ${ }^{2}$ Department of Engineering Sciences, Uppsala University, Uppsala, Sweden \\ Email: Boel.Ekergard@hv.se
}

How to cite this paper: Ekergård, B. and Leijon, M. (2021) Eddy Current Losses in Solid Pole Shoes in a Two-Pole Permanent Magnet Motor. Engineering, 13, 536-543. https://doi.org/10.4236/eng.2021.1310038

Received: August 17, 2021

Accepted: October 22, 2021

Published: October 25, 2021

Copyright (C) 2021 by author(s) and Scientific Research Publishing Inc. This work is licensed under the Creative Commons Attribution International License (CC BY 4.0).

http://creativecommons.org/licenses/by/4.0/ (c) (i) Open Access

\begin{abstract}
The aim of this paper is to present the eddy current losses in solid pole shoes in a permanent magnet two-pole electric motor. In the presented paper, the authors have chosen to work with three different analytical models, Carter's theory, Gibb's theory and Lawrenson's theory, each with different degree of accuracy and simplifications. The results from the analytical models all present relatively low eddy current losses, giving the designer valuable arguments to utilize solid pole shoes, as a rotor with solid poles is from a construction point of view a more suitable choice, increasing the mechanical stability and reducing the production cost, compared to the laminated design.
\end{abstract}

\section{Keywords}

Electrical Machines, Rotor Core Losses, Permanent Magnet Motor

\section{Introduction}

The energy challenge linked to the transport sector is seen as one of the most important challenges in the International Energy Agency's evaluation [1]. As almost $30 \%$ of the world's power needs are consumed in the transport sector, there is great interest in further developed electric propulsion systems, which offer a much higher efficiency than the internal combustion engine and reduce greenhouse gas emissions to zero [2].

One of the most important parts of an electric driveline is the electric motor, converting electric energy to kinetic energy, which shall be designed with a high efficiency over a wide frequency range, to minimize issues with heat and be able to deliver the required torque at each time and sequence.

During the energy conversion within the electrical machine, a certain amount of power is converted to heat, lost in losses. The losses developed in the iron core 
are known as core losses. Core losses have always been an important subject in the design of an electric machine. Reports of improved analytical and numerical models including for example rotational losses, harmonics and developed material models [3]-[11] can be found in the literature.

The variation of the permeance in the air gap rose from stator slotting results in a non sinusoidal flux density wave form in the air gap. The high frequency harmonics rotate the asynchronous relative rotor, inducing eddy currents in all electric conductive parts of the rotor. Numerical calculations are often, due to the high accuracy, at great favor when calculating the core losses and the above the presented areas of investigations are often solved with complex time-consuming and expensive numerical calculations. However, to gain a deeper knowledge and understanding and to avoid a non-correct solution from the numerical calculations due to limitations in the mesh size and boundary conditions within a reasonable time-frame, the authors argue for the need of analytical calculations as a complement to the numerical calculations.

Hence, in this paper, investigations of the eddy current losses in a rotor of a two-pole permanent [12] magnet motor are calculated with three different analytical models. As high efficiency and mechanical stability of the electrical motor in an electrical driveline are prioritized objects, the authors aim to study the size of the eddy current losses in solid pole shoes, as a rotor with solid poles is from a construction point of view a more suitable choice, increasing the mechanical stability and reducing the production cost.

\section{Machine Model}

This paper is focusing on a two-pole permanent magnet motor, designed to be implemented in an All Electric Propulsion System. The magnetic material is in the design located in the middle of the rotor, embedded between two solid pole-shoes, presented in Figure 1.

The motor is designed with circular conductors, based on the Powerformer concept. The choice to work with cable winding is done with the physical background of Maxwell and Poynting in mind. B. Bolund [13] present detailed studies of the electric field distribution on different shapes of conductors, all with strongly benefits of the circular design, where the distribution of the electrical field is smooth, without hot spots which can be seen in, for example in the corner within a rectangular winding. The dimension is set by the voltage and power rating of the motor, where the number of slots per pole and phase, cables per slot and the magnetic circuit is designed with high efficiency and the total weight in mind.

To be able to evaluate how different values of the permeability of the steel affects the results, the author has chosen to perform the analytical calculation for each analytical theory at three different electrical loading of the electrical motor.

The electric dimensions of the motor at the chosen calculation setups are presented in Table 1. 


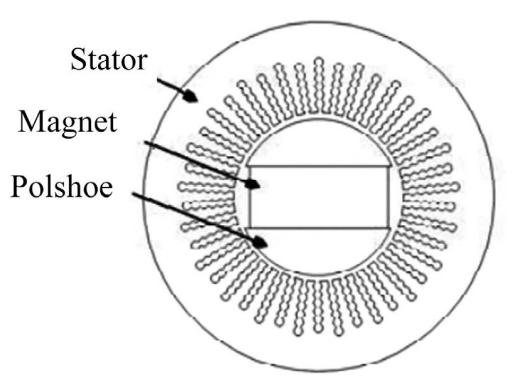

Figure 1. View of the electric motor.

Table 1. The electrical parameters of the motor [12].

\begin{tabular}{cccc}
\hline & No Load & Full Load & 100\% Overload \\
\hline Power $[\mathrm{kW}]$ & 0 & 30 & 60 \\
Current density $\left[\mathrm{A} / \mathrm{mm}^{2}\right]$ & 0 & 3.3 & 6.6 \\
Frequency $[\mathrm{Hz}]$ & 50 & 50 & 50 \\
Power Factor & - & 1 & 1 \\
Load angle $\left[{ }^{\circ}\right]$ & 0 & 20 & 35 \\
\hline
\end{tabular}

\section{Material and Methods}

Iron losses in an electric machine are divided into eddy current losses, hysteresis losses and excess losses, calculated as: [3]

$$
P_{F e}=k_{f} k_{\text {eddy }}\left(B_{\max } f\right)^{2}+k_{f} k_{h y} B_{\text {max }}^{2} f+k_{f} k_{\text {exc }}\left(B_{\max } f\right)^{1.5}[\mathrm{~W} / \mathrm{kg}]
$$

where $k_{f}$ is the stacking factor, $k_{e d d y}$ is the eddy current loss coefficient, $k_{h y}$ is the hysteresis loss coefficient, $k_{\text {exc }}$ is the excess loss coefficient, $B_{\max }$ is the peak magnetic flux density and $f$ is the frequency [3].

In order to reduce the eddy current loss and to ensure that the stator steel can transmit the required magnetic flux, i.e. reduce the eddy currents so the reaction field is not great enough to counteract the main field, the stator of an electrical machine is laminated. The width of each sheet shall not be thicker than half the skin depth, $\delta$, defined as:

$$
\delta=\sqrt{\frac{2}{\omega \sigma \mu_{0} \mu_{r}}}[\mathrm{~m}]
$$

$\omega$ is the angular frequency, $\sigma$ is the conductivity of the steel, $\mu_{0}$ is the permeability in vacuum and $\mu_{r}$ represents the relative permeability of the steel [3].

Within the laminated stator, the eddy currents are constrained by the absent of space and high resistivity and is thereby greatly reduced in magnitude. The current is known as resistance-limited, and the eddy current loss coefficient is calculated according to:

$$
k_{\text {eddy }}=\pi^{2} \frac{\sigma d^{2}}{6}\left[\mathrm{~S} \cdot \mathrm{m}^{4} \cdot \mathrm{kg}^{-1}\right]
$$

where $\sigma$ is the conductivity and $d$ is the steel thickness. 
The variation of the permeance in the air gap raised from stator slotting results in a non sinusoidal flux density wave form in the air gap [4]. The high frequency harmonics rotates asynchronous relative the rotor, inducing eddy currents in all electric conductive parts of the rotor with a skin depth, $\delta$, equal to Equation (2). In such a design, the solid pole thickness is much greater than the skin depth, $\delta$ and hence, the induced eddy current distribution is not limited by lack of space and high resistivity as in a laminated design, but mainly by its own field. The currents are known as inductance-limited and can thereby not be calculated by Equation (1) and Equation (3). Different analytical models have been developed to calculate the size of inductance-limited eddy current losses, three of them are further described below.

\subsection{Carter's Theory}

The first analytical theorem presented in this subject, known to the author, was developed by F. W. Carter, presented in the paper: Pole-face losses from 1915 [14]. The theorem argues for not including the reaction effects from the eddy currents in the calculations, i.e. the ripple can be found from the air gap flux at a static situation, and the saturation of the rotor steel can be neglected. Carter thereby utilizes a constant value for the permeability, independent on the level of saturation and calculates the eddy current losses in solid material with Equation (4):

$$
P_{\text {eddy }}=\frac{1}{8 \pi} q^{0.5} v^{1.5} \rho^{-0.5} \mu^{-0.5} B^{\prime 2}[\mathrm{~W}]
$$

where $B$ 'is the amplitude of the variation, $v$ the velocity, $q$ the tooth pitch and $\mu$ represent the permeability of the non-saturated steel. As written above, the term $B$ 'is determined from the air gap flux at a static situation.

\subsection{Gibb's Theory}

Inspired by the work performed by Carter, Gibb's presents in Ref. [15] a further developed model, which in line with Carter's theory ignores the reaction field from the eddy currents [6], i.e. the ripple can be found from the air gap flux at a static situation, but in contrary the theorem includes the variations on the steel's saturation level and harmonics. The analytical model presented by Gibb's has been verified with both experimental and numerical calculations at different levels of saturation, presented in [15] [16].

\subsection{Lawrenson's Theory}

Lawrenson continued the development of the analytical model, and in [17] Lawrenson presented a theory where the reaction field from the eddy currents is included in the calculations. The ripple of the magnetic flux density in the air gap can thereby not be found directly from a static situation, as in previous models, and instead the value shall be adapted to a dynamic situation. In Paper [17] Lawrenson present the theory and assumptions resulting in Equation (6).

$$
P_{\text {eddy }}=\frac{B 2 v}{4 p \operatorname{Rey}}\left[\mathrm{W}^{1}\right]
$$



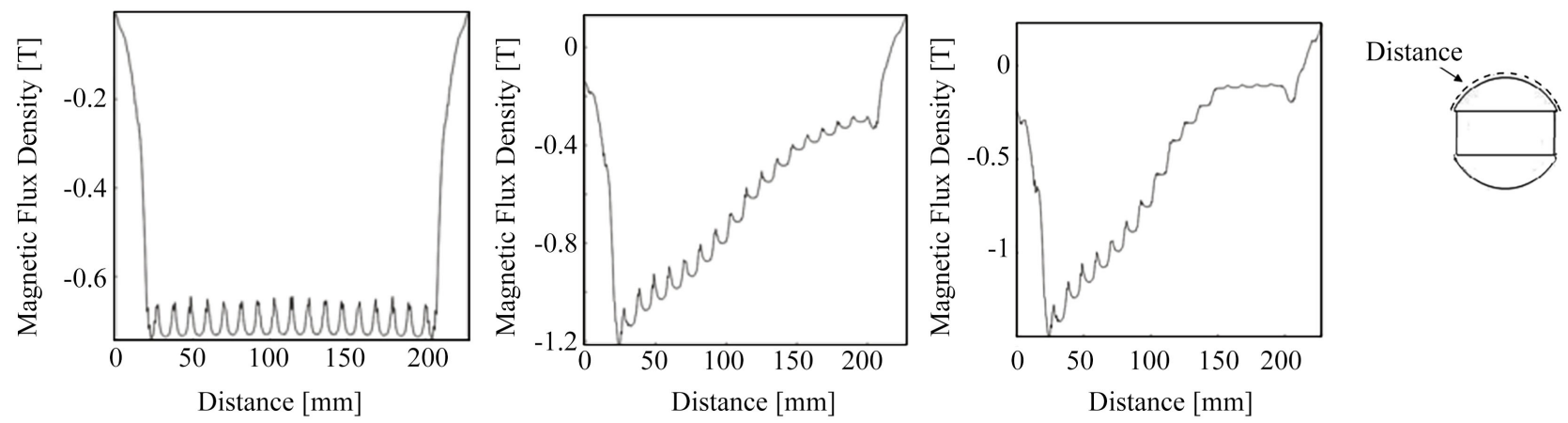

Figure 2. The magnetic flux density variation in the air-gap at: To the left) No Load, The middle) Full Load and The right) $100 \%$ Overload [12]. The dotted line, seen above the rotor in the upper corner to the right represent the variable "Distance".

Table 2. The three different models.

\begin{tabular}{ccc}
\hline Loss Model & Saturation & Reaction field \\
\hline Carter's Theory & Ignores & Ignores \\
Gibbs' Theory & Include & Ignores \\
Lawrenson's Theory & Include & Include \\
\hline
\end{tabular}

Table 3. The value of the flux oscillation factor, the harmonic factor and $\mathrm{H}_{\text {tangential. }}$

\begin{tabular}{cccc}
\hline & No Load $[\mathrm{W}]$ & Full Load $[\mathrm{W}]$ & 100\% Overload [W] \\
\hline Flux oscillation factor & 0.05 & 0.05 & 0.05 \\
Harmonic factor & 1.1 & 1.1 & 1.1 \\
$\mathrm{H}_{\text {tangential }}[\mathrm{A} / \mathrm{m}]$ & 591 & 940 & 1293 \\
\hline
\end{tabular}


Table 4. The losses for each theory and each loading.

\begin{tabular}{cccc}
\hline Loss Model & NoLoad $[\mathrm{W}]$ & Full Load $[\mathrm{W}]$ & $100 \%$ Overload $[\mathrm{W}]$ \\
\hline Carter's & 14 & 32 & 57 \\
Gibb's & 22.5 & 42 & 58 \\
Lawrenson's & 20 & 39 & 50 \\
\hline
\end{tabular}

\section{Discussion}

The paper presents how three different analytical models, each with different degree of accuracy and simplifications, have been utilized to calculate the eddy current losses in the rotor in a permanent magnet two pole electric motor. As high efficiency and mechanical stability are prioritized objects, the argumentation of the study is the interest of the size of the eddy current losses in solid pole shoes, as a rotor with solid poles is from a construction point of view a more suitable choice, increasing the mechanical stability and reducing the production cost.

For this geometry of the electric motor, the three different theories all reaches the same results. As the main purpose of the study, resulting in this paper, was to identify a need or not a need of laminating the rotor, the author is satisfied with the work, but to further analyse the different theories, the next step within the work would be to evaluate different geometries, for example, different length of the air gap and tooth pitch to fully understand how the models different degree of accuracy affects the results. A smaller air gap, which will increase the magnetic field in the electrical machine, will probably increase the difference and accuracy of the results. A smaller tooth pitch will probably affect the results in the same way. Smaller tooth pitch results in a locally higher value of the magnetic field, increasing the ripple and therefore the losses.

Even though the motor is designed with a relative low value of the magnetic flux density in the rotor surface, the saturation has a great impact on the losses, clearly noticing when the reader compares the size of the losses from the three different models at the three different loading cases. As expected, the losses decreases when the authors include the reaction field, done with help from Lawrenson's model.

\section{Conclusions}

As expected, the model which presents the greatest losses was Gibb's theory, as it includes saturation but does not take the reaction field into account.

As all three analytical models present eddy current losses in the solid pole shoes of approximate $0.1 \%$ of the output power, the author states that lamination of the rotor for this design is not required. A rotor with solid poles is in favour and a more suitable choice, increasing the mechanical stability and reducing the production cost.

In Ref. [17] Lawrenson concludes that the size of the losses depends on the 
length of the air gap and on the permeability in the pole material. As this paper only discusses one geometry of an electric motor, the same conclusion can here not be drawn, but the author reaches the same conclusion regarding the impact of the permeability.

\section{Conflicts of Interest}

The authors declare no conflicts of interest regarding the publication of this paper.

\section{References}

[1] Sverige ledande i energiomställning enligt utvärdering av Internationella energibyrån (IEA).

https://www.regeringen.se/artiklar/2019/04/sverige-ledande-i-energiomstallning-enl igt-utvardering-av-internationella-energibyran-iea/

[2] Santiago, J., Bernhoff, H., Ekergård, B., Eriksson, S., Apelfröjd, S., Waters, R. and Leijon, M. (2012) Electrical Motor Drivelines in Commercial All Electric Vehicles: A Review. IEEE Transactions on Vehicular Technology, 61, 475-484. https://doi.org/10.1109/TVT.2011.2177873

[3] Stoll, R.L. (1974) The Analysis of Eddy Currents. Oxford University Press, Oxford.

[4] Ranlöf, M. and Lundin, U. (2011) On Permeance Modeling of Large Hydrogenerators with Application to Voltage Harmonics Prediction. IEEE Transactions on Energy Conversion, 25, 1179-1186. https://doi.org/10.1109/TEC.2010.2040740

[5] Holmberg, P., Leijon, M. and Wass, T. (2003) A Wideband Lumped Circuit Model of Eddy Current Losses in a Coil with a Coaxial Insulation System and a Stranded Conductor. IEEE Transactions on Power Delivery, 18, 50-60. https://doi.org/10.1109/TPWRD.2002.803753

[6] Drubel, O. and Stoll, R.L. (2001) Comparison between Analytical and Numerical Methods of Calculating Tooth Ripple Losses in Salient Pole Synchronous Machines. IEEE Transactions on Energy Conversion, 16, 61-67. https://doi.org/10.1109/60.911405

[7] Xu, L., Zhao, W., Li, R. and Niu, S. (time) Analysis of Rotor Losses in Permanent Magnet Vernier Machines. IEEE Transactions on Industrial Electronics, 1.

[8] Wang, Y., Xu, W., Zhang, X. and Ma, W. (2020) Harmonic Analysis of Air Gap Magnetic Field in Flux-Modulation Double-Stator Electrical-Excitation Synchronous Machine. IEEE Transactions on Industrial Electronics, 67, 5302-5312. https://doi.org/10.1109/TIE.2019.2934061

[9] Caunes, A., Takorabet, N., Chaithongsuk, S. and Duranton, L. (2019) Characterization of Rotor Losses in High Speed Permanent Magnet Synchronous Machines. 19th International Symposium on Electromagnetic Fields in Mechatronics, Electrical and Electronic Engineering, Nancy, 29-31 August 2019, 1-2. https://doi.org/10.1109/ISEF45929.2019.9097096

[10] Castagnaro, E., Bacco, G. and Bianchi, N. (2018) Rotor Iron Losses in High-Speed Synchronous Reluctance Motors. XIII International Conference on Electrical Machines, Alexandroupoli, 3-6 September 2018, 1310-1316. https://doi.org/10.1109/ICELMACH.2018.8506888

[11] Bettayeb, A., Kaczmarek, R. and Vannier, J.C. (2010) Analytical Estimation of Rotor Loss due to Stator Slotting of Synchronous PM Machines. International Journal of 
Electrical, Computer, Energetic, Electronic and Communication Engineering, 4, 915-921.

[12] Leijon, M., Ekergård, B., Apelfröjd, S., De Santiago, J., Bernhoff, H., Waters, R. and Eriksson, S. (2013) On a Two Pole Motor for Electric Propulsion System. International Journal of Engineering Science and Innovative Technology, 2, 99-111.

[13] Bolund, B., Leijon, M. and Lundin, U. (2008) Poynting Theorem for Cable Wound Generator. IEEE Transaction on Dielectrics and Electrical Insulation, 15, 600-605. https://doi.org/10.1109/TDEI.2008.4483482

[14] Carter, F.W. (1916) Pole-Face Losses. Journal of the Institution of Electrical Engineers, 54, 168-170. https://doi.org/10.1049/jiee-1.1916.0005

[15] Gibbs, W.J. (1947) Tooth-Ripple Losses in Unwound Pole-Shoes. Journal of the Institution of Electrical Engineers, 94, 2-12.

[16] Oberretl, K. (1972) Eddy Current Losses in Solid Pole Shoes of Synchronous Machines at No-Load and on Load. IEEE Transactions on Power Apparatus and Systems, PAS-91, 152-160. https://doi.org/10.1109/TPAS.1972.293325

[17] Lawrenson, P.J., Reece, P. and Ralph, M.C. (1966) Tooth-Ripple Losses in Solid Poles. Proceedings of the Institution of Electrical Engineers, 113, 657-662. https://doi.org/10.1049/piee.1966.0106 